Revista Iberoamericana, Vol. LXXV, Núm. 227, Abril-Junio 2009, 475-486

\title{
LITERATURA/ENFERMEDAD: EL CUERPO COMO DESECHO. UNA LECTURA DE SALÓN DE BELLEZA DE MARIO BELLATIN
}

\author{
POR \\ Alicia Vaggione \\ Universidad Nacional de Córdoba
}

La narrativa de Mario Bellatin, que se caracteriza por crear universos cerrados que se ajustan a sus propias reglas, rodea e indaga en forma continua los temas de la orfandad, de la enfermedad, de los cuerpos deformes, mutilados o monstruosos. Aborda cuestiones inquietantes desde una prosa helada, ajena a toda afección, que avanza a partir de fragmentos. Los materiales sociales e históricos que ingresan a sus textos se vuelven en su proyecto de escritura una cuestión formal.

La figura de Bellatin -en tanto autor-se conecta fuertemente con su obra. En entrevistas y suplementos culturales, es común encontrar una pequeña biografía que insiste en resaltar dos o tres hechos escuetos; mexicano, hijo de padres peruanos, vivió parte de su vida en Perú, estudió teología, es profesor universitario y realizó estudios de cine en Cuba. Desde el año 2000 dirige una escuela de escritura en México, conocida como Escuela Dinámica de Escritores, ${ }^{1}$ y sus obras han sido traducidas a varios idiomas y ganado importantes premios. ${ }^{2} \mathrm{~A}$ estas presentaciones del escritor se suma, como anécdota recurrente, el decir que cuenta con un brazo ortopédico.

\footnotetext{
1 La Escuela Dinámica de Escritores, en palabras de Bellatin, es una "escuela vacía donde no hay programas de estudio". Concebida como un espacio que se diferencia tanto del taller literario como del espacio académico, la escuela se establece como un lugar "donde se examinan asuntos no sólo relacionados con la literatura sino, especialmente, con las maneras que tienen las demás artes de estructurar sus narraciones". Se piensa como un sitio de reflexión sobre la literatura y sus procedimientos, partiendo del postulado de que "no se puede, no se debe, enseñar a ser escritor" (“Una escuela..." 23).

2 Laproducción narrativa de Mario Bellatin está compuestapor Mujeres de sal(1986), Efecto invernadero (1992), Canon perpetuo (1993), Damas chinas (1995), Poeta ciego (1998), El jardín de la señora Murakami (1999), Flores (2000), Shiki Nagaoka, una nariz de ficción (2001), La escuela del dolor humano de Sechuán (2001), Jacobo el mutante (2002) y Perros héroes (2003). Por su novela Flores obtuvo el premio Xavier Villaurrutia en 2001 y Salón de belleza fue finalista al Premio Médicis a la mejor novela extranjera editada en Francia en el año 2000.
} 
En este trabajo me interesa concentrarme en el estudio de una de sus novelas, Salón de belleza, publicada en el año 1994, con el objeto de entrever cómo la literatura opera y genera representaciones de la enfermedad, del cuerpo y de la muerte.

En Salón de belleza lo que aparece es la presencia de una enfermedad regida por la metáfora de la peste en la medida que suscita, como lo estudiara Foucault, afanes de separación, exclusión y purificación.

La anécdota principal da cuenta de lo que sucede en un espacio, el salón de belleza, que ha sufrido una mutación radical al convertirse en un lugar a donde van a pasar sus días los enfermos terminales. El relato está a cargo de un narrador en primera persona, un peluquero, travesti, enfermo también él, que ha decidido marcar la distinción de su salón decorándolo con grandes acuarios.

En la novela de Bellatin, los cuerpos enfermos, que son descriptos como contaminados, invadidos, aprisionados y desfigurados por la enfermedad, son presentados no sólo como cuerpos que sobran sino también como cuerpos a los que hay que eliminar. Particularmente, me interesa concentrarme en este pasaje, en esta frontera, en la que se opera un deslizamiento en el que el cuerpo enfermo deviene puro desecho, puro material en el que ya no puede inscribirse ninguna forma de identidad ni ninguna forma de derecho.

Las reflexiones de Giorgio Agamben abren un espacio importante para pensar estos cuerpos desechables:

El estado de excepción, que era esencialmente una suspensión temporal del orden jurídico, se hace ahora un nuevo y estable sustrato espacial en el que habita esa nuda vida que, de forma cada vez más evidente, ya no puede ser inscripta en el orden jurídico. (223)

DEL SALÓN DE BELLEZA AL MORIDERO

La dimensión central del texto se juega en relación al espacio y sus sucesivas transformaciones. Como mencionamos anteriormente, la anécdota principal del texto da cuenta de lo que sucede en un espacio, el salón de belleza, que ha sufrido o sobre el que se ha operado una mutación radical al convertirse en un lugar a donde van a pasar sus días los enfermos terminales, en palabras del texto, un "moridero".

El viejo esplendor del salón de belleza donde se acicalaba la cabellera de las mujeres se ha convertido ahora en un espacio mórbido y fétido. Los espejos han sido retirados, los acuarios otrora cristalinos y repletos de peces se encuentran contaminados y casi vacíos: “Ahora que el salón se ha transformado en un Moridero, donde van a terminar sus días quienes no tienen dónde hacerlo, me deprime ver cómo poco a poco los peces han ido desapareciendo" (11). ${ }^{3}$

3 Todas las citas pertenecientes a Salón de belleza corresponden a la edición de Tusquets, México, 2003. En adelante sólo se indicará el número de página. 
No obstante, como continuidad, en el plano de este cambio radical, podemos pensar en la presencia de ciertas prácticas sobre el cuerpo que se ejercen de diferente modo según se trate del espacio del salón de belleza o del moridero.

Prácticas que, en primer lugar, procuran su transformación con el propósito de embellecerlo (estamos en la dimensión de una estética) y, posteriormente, prácticas de asistencia que acompañan a un cuerpo próximo a su fin, en estado terminal, brindándole los cuidados básicos e indispensables (estamos en el límite difuso, en ese espacio intermedio en el que un cuerpo está vivo pero tiene en sí todas las marcas de la muerte).

Estos cuidados forman parte del hacer diario del narrador-protagonista y se efectúan a modo de pequeños rituales asistenciales y disciplinarios que consisten en asistir, controlar, higienizar, dar alimento:

...desde temprano salía al mercado a comprar las verduras con las que hacía las sopas diarias. Después de regresar, pasaba revista a los huéspedes y luego los limpiaba lo mejor posible [...] A la hora del almuerzo servía los platos. Era la única comida. Los huéspedes casi nunca tenían hambre y muchos de ellos ni siquiera terminaban el plato diario de sopa que les ponía enfrente... (38)

El cuerpo que se presenta va perdiendo su autonomía, sus instancias vitales, sus necesidades básicas, avanza hacia el puro desecho. Es importante marcar que el cuerpo es concebido en su instancia terminal, la novela no construye un espacio para la "sobrevida". El concepto de "sobrevida" que es aplicado por la medicina para marcar la zona de posibilidad que se abre, en tanto margen de vida, cuando se declara una enfermedad terminal, conlleva un sinnúmero de interrogantes desde un punto de vista filosófico-existencial. ${ }^{4}$

\footnotetext{
4 Este concepto, de por sí problemático, es trabajado por Giorgio Agamben en relación a una figura extrema: el ultracomatoso -estudiada en 1959 por dos neurofisiólogos franceses- que se define en relación a la abolición total de las funciones de la vida de relación (conciencia, movilidad, reflejos) junto con la abolición total de todas las funciones de la vida vegetativa (respiración, circulación, termorregulación). Agamben señala que el interés de esta figura va mucho más allá del problema científico de la reanimación dado que "lo que estaba en juego era nada más y nada menos que la definición de muerte”(205). Además: “la cuestión se hacía más urgente [...] por el hecho de que [...] los progresos de las técnicas de reanimación que habían permitido la aparición del ultracomatoso habían surgido al mismo tiempo que las tecnologías de transplante” (205). También, y en otro orden, el filosófo francés Jean-Luc Nancy reflexiona sobre el concepto de "sobrevida" en un texto titulado El intruso donde cuenta su experiencia de un transplante de corazón. Nancy reflexiona: "Mi sobrevida está inscripta en un proceso complejo tejido entre extraños y extrañezas [...] ¿Cuál es la obligación de hacerme sobrevivir? [...] ¿ Por qué yo? ¿Por qué sobrevivir en general? ¿Qué significa sobrevivir?” (22). Los interrogantes de Nancy apuntan al centro de la relación entre política y vida en la contemporaneidad.
} 
Estos cuerpos sobre los que no cabe ninguna posibilidad de futuro son los que habitan el moridero, aunque el término habitar posee demasiadas connotaciones vitales. Tal vez sería conveniente decir que estos cuerpos son los que forman parte del moridero, que aparece como un espacio cada vez más concurrido, más transitado, a medida que la enfermedad se disemina:

...es cada vez mayor la cantidad de personas que ha venido a morir al salón de belleza. Ya no solamente amigos en cuyos cuerpos el mal está avanzado, sino que la mayoría se trata de extraños que no tienen donde morir. Además del Moridero, la única alternativa sería perecer en la calle... (14)

El moridero aparece como un espacio que intenta evitar la desprotección extrema, que da refugio a quienes son abandonados y están solos.

Pero este espacio, que funciona como lugar para quienes no tienen donde estar, es también, y fundamentalmente, un espacio de encierro y confinamiento que convoca simultáneamente el imaginario ${ }^{5}$ de la lepra y su exclusión, y el de la peste y su esquema disciplinario. Para Michel Foucault la lepra y la peste representan esquemas diferentes pero no incompatibles. ${ }^{6}$ En relación al espacio, la lepra representa el modelo del encierro: "El leproso está prendido en una práctica del rechazo, del exilio-clausura” (202) mientras la peste tiene como correlato la disciplina. Foucault estudia cómo las primeras medidas que había que adoptar cuando se declaraba la peste en una ciudad incluían, en primer lugar, la división del espacio: "Este espacio cerrado, recortado, vigilado, en todos sus puntos, en el que los individuos están insertos en un lugar fijo, en el que los menores movimientos se hallan controlados [...] todo esto constituye un modelo compacto de dispositivo disciplinario" (201).

El moridero, entonces, opera como un espacio en el que convergen los esquemas de las enfermedades trabajadas por Foucault. Funciona como espacio de encierro,

5 Utilizo este término porque la enfermedad que aparece en el texto, enfermedad que nunca es nombrada, que nunca es especificada directamente, posibilita la actualización de viejas metáforas de la enfermedad correspondientes a enfermedades históricas determinadas. Estoy pensando en términos de Susan Sontag y en sus ensayos sobre el cáncer y sobre el sida en los que trabaja cómo el imaginario de estas enfermedades contemporáneas está atravesado por significaciones que en el pasado se asociaron a la sífilis, a la lepra y a la peste.

6 "Lentamente, se les ve aproximarse, y corresponde al siglo xix haber aplicado al espacio de la exclusión cuyo habitante simbólico era el leproso la técnica de poder propia del reticulado disciplinario. Tratar a los 'leprosos' como 'apestados', proyectar los desgloses finos de la disciplina sobre el espacio confuso del internamiento, trabajarlo con los métodos de la distribución analítica del poder, individualizar a los excluidos, pero servirse de los procedimientos de individualización para marcar exclusiones, esto es lo que ha sido llevado a cabo regularmente por el poder disciplinario desde los comienzos del siglo XIX” (203). 
de "exilio-clausura" de unos cuerpos contaminados y abandonados allí hasta su muerte próxima. Y también funciona como espacio amenazante-el único personaje que tiene la posibilidad de entrar y salir del moridero es su regente-como territorio maldito y estéril al que hay que vigilar y que se pretende eliminar: "Cuando la gente quiso quemar el salón tuvo que intervenir hasta la misma policía. Los vecinos afirmaban que aquel lugar era un foco infeccioso, que la peste había ido a instalarse en sus dominios” (34).

Finalmente, la escena del ataque no termina de concretarse por el miedo a los que están allí encerrados: “... la turba había logrado violar la puerta principal. Sin embargo, por alguna razón que intuyo relacionada con los olores o el temor al contagio, no habían entrado" (37). El olor nauseabundo que despiden estos cuerpos que se descomponen en vida, el temor que producen marca un límite que parece posibilitar la persistencia del moridero que está ubicado en el centro de un barrio marginal, esto es como un espacio central en el marco de una periferia. Esta inscripción topológica, que lleva en sí misma la marca de una dislocación, un centro que es en sí mismo periférico, circunscribe una zona de excepción donde se inscriben estas vidas despojadas de todo valor.

A partir de estas operaciones es como si Bellatin jugara con la construcción y la creación de un espacio de confinamiento y exclusión que permite reunir y agrupar a un grupo de sujetos despojados de toda identidad que no sea la de una muerte inminente.

Los espacios de encierro son característicos, además, de otros trabajos de Bellatin. Los asilos o internados para niños nacidos con malformaciones son espacios que aparecen en Lecciones para una liebre muerta y en Flores. En Lecciones... -texto en el que el autor recupera Salón de belleza y las lecturas a que ha dado lugar-se construye un espacio denominado “ciudadela final”, donde se interna forzosamente a las personas afectadas por enfermedades transmisibles fundamentalmente por temor al contagio. Y unos personajes denominados "universales" piden ser encerrados a pesar de no padecer enfermedad alguna.

Con estas operaciones la literatura de Bellatin logra complejizar y tornar indiscernible la delimitación entre un adentro y un afuera. Los espacios que se actualizan en sus textos se conectan con esas zonas confusas, pero específicamente definidas, donde hace su irrupción la nuda vida en el marco del orden jurídico, la vida despojada de todo valor y de todo derecho.

DE LOS DESTELLOS DE LOS GÉNEROS DORADOS A LAS ROPAS APILADAS DEL MORIDERO

Como dijimos, la historia que se nos cuenta está a cargo de un narrador en primera persona que es el personaje central del texto. Enfermo, peluquero y travesti, 
los dos últimos términos se conectan en lo referente a la construcción de una estética; embellecer al otro y ofrecerse a su mirada como cuerpo femenino:

En un letrero colocado en la entrada, se señalaba que era un local donde recibían tratamiento de belleza personas de ambos sexos. Sin embargo, era muy reducido el número de hombres que cruzaba el umbral. Sólo a las mujeres parecía no importarles la atención de unos estilistas vestidos siempre con ropas femeninas. (23)

Respecto de la sexualidad del personaje principal, dos prácticas aparecen en el texto: la asistencia a los saunas y las salidas al centro vestido de mujer. En los dos casos, la aparición de la enfermedad opera una interrupción de estas prácticas, dibuja un contorno que permite delimitar un “antes” donde la experiencia del afuera es posible y un "ahora" que se relaciona directamente con el espacio cerrado del moridero.

Los efectos de desfiguración que produce la enfermedad sobre el cuerpo clausuran la posibilidad de asistencia a los saunas: "Actualmente mi cuerpo esquelético, invadido de llagas y ampollas, me impide seguir frecuentando ese lugar” (20). Los paseos al centro también se interrumpen abruptamente:

Mas al descubrir las heridas en mi mejilla las cosas acabaron de golpe. Llevé los vestidos, las plumas y las lentejuelas al patio donde está el excusado e hice una gran pira. [...] Al encender la pira me había puesto uno de los trajes y estaba totalmente mareado. Recuerdo que bailaba alrededor del fuego [...] Mi intención era caer también en el fuego. Ser envuelto por las llamas y desaparecer antes de que la lenta agonía fuera apoderándose de mi cuerpo. (55)

Quemar la ropa resplandeciente usada para la fiesta, concebirla de ahora en más como un objeto inútil. El escritor Luis Gusmán en su estudio Epitafios. El derecho a la muerte escrita explora la relación de contiguidad entre la ropa del difunto y su cuerpo: "La ropa de un muerto es quizás el último vestigio de una intimidad que se ha perdido" (102). La quema de la ropa por parte del protagonista aparece entonces como un primer gesto de despojo y desprendimiento que funciona como anticipo de una muerte que se prevé cercana.

En el orden intersubjetivo, las derivas por la ciudad vestido de mujer provocan sucesivas violencias, es precisamente un incidente con un travesti ${ }^{7}$ golpeado el motivo inicial que da lugar a la transformación del salón en un sitio para morir:

7 Gabriel Giorgi trabaja esta figura en relación a la literatura de Perlongher: "Por el lado sexual y por el lado social, la loca encarna una transgresión sobre la cual siempre pende una amenaza. Transita en el límite, en una línea de exterminio: allí donde el desafío de ciertos cuerpos se verifica alrededor de una eliminación posible o deseada” (154). 
...siempre buscaba algo dorado para salir vestido de mujer por las noches. Pensaba que llevar algo dorado podía traerme suerte. Tal vez salvarme de un encuentro con la Banda de Matacabros, que rondaba por las zonas centrales de la ciudad. Muchos terminaban muertos después de los ataques de esos malhechores, pero creo que si después de un enfrentamiento alguno salía con vida era peor. En los hospitales siempre los trataban con desprecio [...] Desde entonces [...] nació en mí la compasión de recoger a alguno que otro compañero [...] Tal vez de esa manera se fue formando este triste Moridero que tengo la desgracia de regentear”. (15)

Son las violencias repetidas y continuas sobre las figuras de los travestis las que crean el origen del moridero en el texto. Un origen sobre el que luego se marca un pasaje, ya no dar asilo a los travestis golpeados, nombrados como "los amigos", sino también a "los extraños" atacados por el mal y que no tienen donde morir.

En el marco de las derivas por las que transita el texto, los destellos de los géneros dorados, usados para el ejercicio de una sexualidad nómade, clandestina y abierta en el marco de la ciudad, son reemplazados en el espacio del moridero por las ropas, puro resto, viejas y desgastadas que los familiares traen para los enfermos o que se reciben como donaciones: "Con la tela fallada que nos donó una fábrica hicimos algunas sábanas. En el patio que hay detrás del galpón donde duermo, separo las ropas en montones” (22).

LAS REGLAS DEL MORIDERO (O DE LA SOLEDAD DEL MORIR)

En este sitio ocupado por aquellos que sólo pueden esperar la muerte hay una serie de reglas que el narrador, regente del moridero (en tanto lo gobierna y dirige), impone en su espacio. De este modo se construye una "zona de excepción”: "El estado de excepción no es, pues, el caos que precede al orden, sino la situación que resulta de la suspensión de éste” (Agamben 30).

En este marco, sólo está permitido que los familiares-que dejan o abandonan allí a sus enfermos-aporten dinero, ropas y golosinas; las medicinas y los tratamientos médicos están prohibidos.

En el moridero sólo se aceptan hombres; el personaje central que semetamorfosea en mujer cierra su espacio a otras mujeres. Cualquier tipo de afecto por parte de familiares, amigos o amantes también está prohibido. El moridero no es un hospital, no hay ninguna esperanza posible para los que están allí encerrados: “el mal no tiene cura" (42).

Y en el marco de este reglamento se destacan dos puntos: al moridero sólo pueden ingresar aquellos enfermos que se encuentren en una fase terminal de la enfermedad; las "víctimas" o "huéspedes" -nombre que reciben los enfermos en el texto- deben permanecer en el anonimato dado que: “...todos no son más que 
cuerpos en trance de desaparición” (25). De este modo, el moridero funciona como antesala de la muerte, el ingreso a este espacio supone la pérdida de la identidad, del nombre propio y el ingreso a una temporalidad en la que se suspende, simultáneamente, la posibilidad de todo pasado ${ }^{8} \mathrm{y}$ de todo futuro que no sea el de una próxima cancelación.

Cuando llega el final:

Los muertos van a dar a la fosa común. Sus cuerpos son envueltos en unos sudarios con las telas de sábanas que nos donaron. No hay velatorio. Se quedan en cama hasta que unos hombres contratados los trasladan en carretillas. No los acompaño, y cuando vienen los familiares a preguntar, me limito a informarles que ya no están más en este mundo. (45)

Todos los rituales de la muerte desaparecen, los cuerpos son envueltos con la ropa fallada, el cuerpo no es más que desecho y es trasladado en carretillas como la basura. El nudo entre cuerpo e inscripción se deshace, no hay tumba.

En el marco de este "estado de excepción” en el que trabaja el texto, en el que la vida se puede sacrificar sin cometer asesinato, todos los derechos están suspendidos, también "el derecho a la muerte escrita” que trabaja Luis Gusmán:

Con la damnatio memoriae, nos introducimos no ya en la identidad perdida sino abolida. En este punto los ejemplos son del orden de lo monstruoso. Bastaría nombrar la experiencia de Robert Antelme que estuvo preso en Dachau. La cita que transcribo y que pertenece a Dionys Mascolo puede leerse en la solapa de su libro titulado irónicamente La especie humana: "Presencia sin identidad. Un Ecce Homo sin sujeto, muestra de nadie, muestra no de un hombre, sino el Hombre reducido a su esencia irreductible”. (18)

LA MUERTE FANTASEADA

Aislar la muerte de la vida, no dejarlas entrelazarse

íntimamente, cada una intrusa en el corazón de la otra: he aquí lo que nunca hay que hacer.

Jean-Luc Nancy, El intruso

Hacia el final del texto el personaje principal reflexiona sobre su propia muerte que presiente próxima y sobre el futuro del moridero tras su desaparición. La idea

8 En el marco de este proceso de desubjetivización puede resonar como contrapartida de lo que sucede en Salón de belleza la frase del narrador de la novela Pájaros de la playa de Severo Sarduy: "Enfermo es aquel que repasa su pasado" (11). 
principal es "eliminar" todos los rastros que pudieran dar cuenta de la existencia de ese espacio y dar lugar nuevamente a los utensilios relacionados con la belleza y a los grandes acuarios de aguas límpidas: “...en el salón estarán las nuevas peceras junto a los flamantes implementos de belleza. No habrá clientes, el único cliente seré yo. Yo solo, muriéndome en medio del decorado...” (70).

En este punto belleza y muerte, que a lo largo del texto se presentaron como mundos próximos pero antagónicos, se unen a partir de la fantasía del personaje para dar lugar a la idea de una estetización de la propia muerte: “...me encontrarán: muerto pero rodeado del pasado esplendor" (71).

Si hasta aquí los espacios de la vida (el salón de belleza) y de la muerte (el moridero) se contraponen, y la belleza se encarna en los grandes acuarios con reminiscencias kitsch, en el acicalamiento de las mujeres, en las ropas de géneros sofisticados, en los cuerpos deseantes que atraviesan la ciudad, en la fiesta, en la compañía, en el estar con los amigos y compañeros; y la muerte como contracara, se metaforiza en los acuarios de aguas contaminadas, en el abandono, en los cuerpos extraños y desfigurados, en la soledad final; podemos decir que con la muerte próxima del protagonista todo se mixtura y la belleza es muerte y la muerte es belleza.

Adviene como dato final el surgimiento de una responsabilidad:

Creo que nunca antes me detenía tanto a pensar. Más bien actuaba. [...] Pero cuando vino todo ese asunto de la transformación del salón se produjo un cambio. Por ejemplo, siempre pienso dos veces antes de hacer algo. Antes no me habría preocupado el futuro del Moridero tras mi desaparición. Habría dejado que los huéspedes se las arreglaran solos. Ahora, sólo puedo pedir que respeten la soledad que se aproxima. (73)

\section{UNA ESCRITURA QUE VUELVE SOBRE SÍ}

En Lecciones para una liebre muerta, novela que se publica once años después que Salón de belleza, Bellatin vuelve sobre el texto y en una especie de "diario de trabajo" retoma y relata cómo fue la escritura de Salón...

De esta manera, la historia de escritura de Salón... se suma a las múltiples historias que, de modo fragmentario pero con una articulación perfecta entre sí, se narran en Lecciones. $^{9}$ Los personajes que aparecen forman conjuntamente una

9 La técnica narrativa de Lecciones... se asemeja a la que se utiliza en Flores, novela publicada en 2000 donde el narrador dice: "Existe una auténtica técnica sumeria, que para muchos es el antecedente de las naturalezas muertas, que permite la construcción de complicadas estructuras narrativas basándose sólo en la suma de determinados objetos que juntos conforman un todo [...] La intención inicial es que cada capítulo pueda leerse por separado, como si de la contemplación de una flor se tratara” (10). 
extraña galería, cada uno con una historia particular: el abuelo del narrador de origen quechua, Macaca y su amante asiático, César Moro al borde de la muerte, el poeta ciego que escribe "El cuadernillo de las cosas difíciles de explicar", el filósofo travesti y sus encuentros con el escritor, etc.

Respecto a la lectura de Salón..., en Lecciones, mario Bellatin -nombre que aparece escrito con minúscula al igual que el título de sus novelas- es un personaje que oficia de escritor y tiene encuentros con otro personaje, el filósofo travesti:

El escritor escuchaba al filósofo travesti en silencio. Sólo de vez en cuando provocaba alguna interrupción para aclarar ciertos puntos. Su actitud se parecía a la de un psiconalista en plena sesión. El travesti filósofo hablaba sin parar. Tenía al escritor como único espejo de sus palabras.

El juego es especular y doblemente interesante, el escritor aparece no sólo como el personaje que escribe sino como aquel que escucha, e interrumpe como un psicoanalista el discurrir del otro; y el filósofo como aquel que no sólo se relaciona con una estética, la de su propia perfomance, sino también con el pensamiento y la verdad. En el plano de esta re-escritura el peluquero-travesti de Salón... ha devenido filósofo, personaje, conectado con la búsqueda del saber.

De esa forma mario bellatin veía, teniendo como fondo las letanías de kant y nietzsche, cómo ese tímido estudiante iba transformándose en la agresiva mujer que, noche tras noche, corría distintos riesgos en sus pesquisas por la ciudad. (107)

Siguiendo con los juegos, se recurre también al cruce de lo biográfico con lo novelístico; produciendo un efecto absolutamente inverosímil el escritor relata cómo durante la escritura de Salón... estuvo rodeado de los espacios acuáticos que en la novela -como vimos- son objeto de un estudio particular.

En el tiempo del filósofo travesti, un amigo le obsequió al escritor un acuario de medianas proporciones [...] Nunca antes el escritor tuvo peceras, quizá por eso le interesó indagar las posibilidades narrativas que podían derivarse de una mirada del mundo acuático. (120)

En otros fragmentos de Lecciones... el escritor vuelve sobre Salón... para referirse a su argumento, y lo hace al modo en que una editorial lo sintetizaría en una contratapa. También se interesa en puntear algunas de las formas en que ha sido leída:

Algunas personas creyeron descubrir la presencia de una enfermedad en particular mientras leían salón de belleza. Otras encontraron similitudes con los morideros 
que en la edad media servían como último lugar para todo género de apestados. Algunos más hallaron una serie de metáforas o puentes entre los peces y los personajes enfermos. (131)

En el marco de estas posibilidades, la primera tiene algunas connotaciones especiales en la medida en que me interesa leer la cuestión de la enfermedad en el texto. Tal vez, es posible leer Salón de belleza como una novela que hace referencia a una enfermedad contemporánea, el sida. Algunos indicios del texto, la descripción de los cuerpos enfermos como cuerpos delgados y esqueléticos, la presencia del ejercicio de una sexualidad nómada y clandestina que la enfermedad viene a clausurar, el temor que producen los enfermos, el contagio, las muertes múltiples, parecen habilitar esta lectura.

Sin embargo, en el proyecto de escritura de Bellatin leer el texto de modo referencial es prácticamente imposible. Si, por un lado, la literatura de Bellatin toma elementos que podemos reconocer como parte del mundo contemporáneo, al ingresar a sus textos se ajustan, se articulan de modo tal que cualquier intento de leerlos en correspondencia con una problemática determinada se vuelve una tarea banal.

La complejidad de los mundos de Bellatin apunta hacia otra parte; tal vez, uno de sus aportes consista en inscribir en sus textos una lógica que tiende, por un lado a mostrar la opacidad a partir de la cual se construye la enfermedad en el mundo contemporáneo, y por otro, a delimitar unas zonas de por sí difusas, pero fuertemente especificadas, en las que se inscriben estas vidas despojadas de valor. La novela de Bellatin interroga la vida biopolíticamente para pensar desde el terreno de la literatura las problemáticas más acuciantes de nuestro tiempo.

CONCLUSIONES: EL LIBRO DE LOS PASAJES

Si en Lecciones para una liebre muerta y en Flores la técnica narrativa de Bellatin tiende a crear, a partir de motivos independientes pero estrechamente relacionados, un efecto de conjunto, Salón de belleza puede leerse como un texto donde predomina la figura del desplazamiento.

En términos estéticos esta novela, que interroga en términos biopolíticos la vida en el presente, puede pensarse como un libro de pasajes donde el procedimiento central consiste en observar cómo un objeto que en principio se presenta luminoso paulatinamente va perdiendo su esplendor.

Salón de belleza trabaja en ese punto intermedio, en ese espacio "entre" la luz y la sombra, la vida y la muerte, para delimitar un tránsito, diseñar un pasaje que muestra el despojo de unos cuerpos. Y pareciera que en un punto Bellatin, que nos hace trastabillar con tanto guiño, lo sabe. 
En el último fragmento que le dedica a Salón... en Lecciones... leemos: “El libro salón de belleza quizá tenga su sentido final en el interés del escritor en responderse ciertas preguntas sobre las posibles relaciones entre belleza y muerte” (132).

BiBLIOGRAFÍA

Agamben, Giorgio. Homo Sacer. El poder soberano y la nuda vida I. Valencia: Pre-Textos, 2003.

Bellatin, Mario. Lecciones para una liebre muerta. Barcelona: Anagrama, 2005. Salón de belleza. Barcelona: Tusquets, 2003.

Flores. Barcelona: Anagrama, 2001.

“Una escuela como una instalación artística”. Otra Parte. Revista de Letras y Artes (Buenos Aires, otoño 2007).

Foucault, Michel. Vigilar y castigar. Nacimiento de la prisión. México: Siglo XXI, 1994.

Giorgi, Gabriel. Sueños de exterminio. Homosexualidad y representación en la literatura agentina contemporánea. Rosario: Beatriz Viterbo Editora, 2004.

Gusmán, Luis. Epitafios. El derecho a la muerte escrita. Buenos Aires: Norma, 2005.

Nancy, Jean-Luc. El intruso. Buenos Aires: Amorrortu, 2006. 